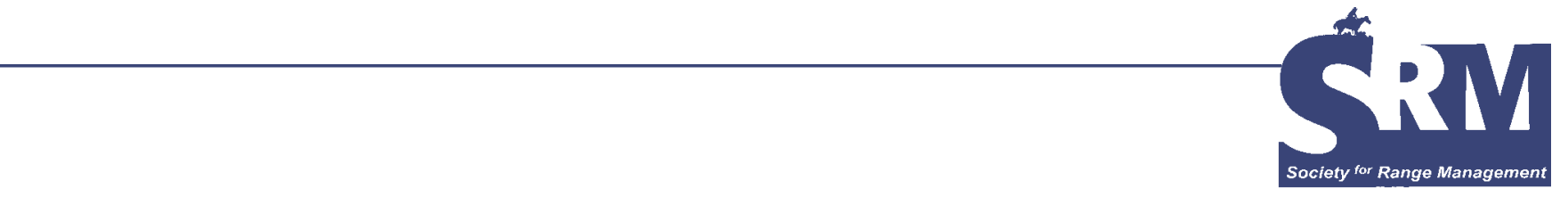

\title{
Speaking With People in Our Profession
}

\section{An interview with Robert Bolton}

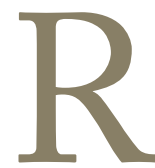

obert Bolton is the Senior Rangeland Management Specialist in the Rangeland Resources Division in the Bureau of Land Management (BLM) Headquarters Office in Washington, DC. In this position he is responsible for developing policy and preparing and issuing budgets for the BLM's Rangeland Management program. Bolton was raised on a wheat and cattle farm in north central Oregon, and graduated from Oregon State University with BS degrees in both Rangeland Management and Wildlife Science. Bob started with the BLM in 1978 and worked as a Range Conservationist and Supervisory Range Conservationist in Elko, Nevada. Later, Bob served as an Area Manager for $9 \mathrm{yr}$ and State Weed Coordinator for $8 \mathrm{yr}$ in Lakeview, Oregon. He worked as a Budget Analyst in the Washington Office Budget Division from 2001 to 2003, and has been in his current position in DC since 2003. Bob, his wife, and 13-yr-old daughter (and two Border Collies) own and operate an organic grass-fed livestock farm in Maryland raising beef, lamb, goats, paint horses, and free-range poultry (layers, broilers, heritage turkeys). He found a few minutes during a typical busy day to answer an array of questions about the BLM and his perspectives on rangeland management.

\section{Trying to Get Back to the Management of} Land

Question: Somehow, an agency name of "Bureau of Land Management" doesn't seem to capture what you and the BLM are trying to do in the 21st Century on hundreds of millions of acres of public rangeland, does it?

Answer: It would be hard to truly capture what we do in just a few words. However, the four-word term "Bureau of Land Management" actually does capture the two central aspects of our mission-land and its management. This name actually does a nice job of describing our key responsibilities.

\section{Should the old sarcastic moniker of the "Bureau of Livestock and Mining" finally and forcefully be put to rest?}

Yes. A few folks might still bring this up on rare occasion. But, since 1976 with the passage of the Federal Land Policy and Management Act, we really have become a multiple-use agency. Today, we are really dealing with many different uses, and working to balance our management of these many uses. It is inappropriate to think of us in terms of just two uses.

\section{How do you bridge the potential disconnect} between an agency headed by a political appointee based in Washington, DC with a resource base primarily west of the 100th meridian?

I came to this job in DC from years of working in the field in the western United States. Since I've been here I've learned how important it is for us to have our headquarters in the DC area. This is where policy is made, and this is where many of our partner agencies and institutions are based. We need to work effectively here in DC in order to have a positive effect out in the field. However, it is obvious to me that it is very critical that all of us based in DC work to stay connected with the field and the people working in the field. This is why our meetings and our professional societies are so important. We can use these field-based activities to allow those of us in the East to remain connected to the field. 


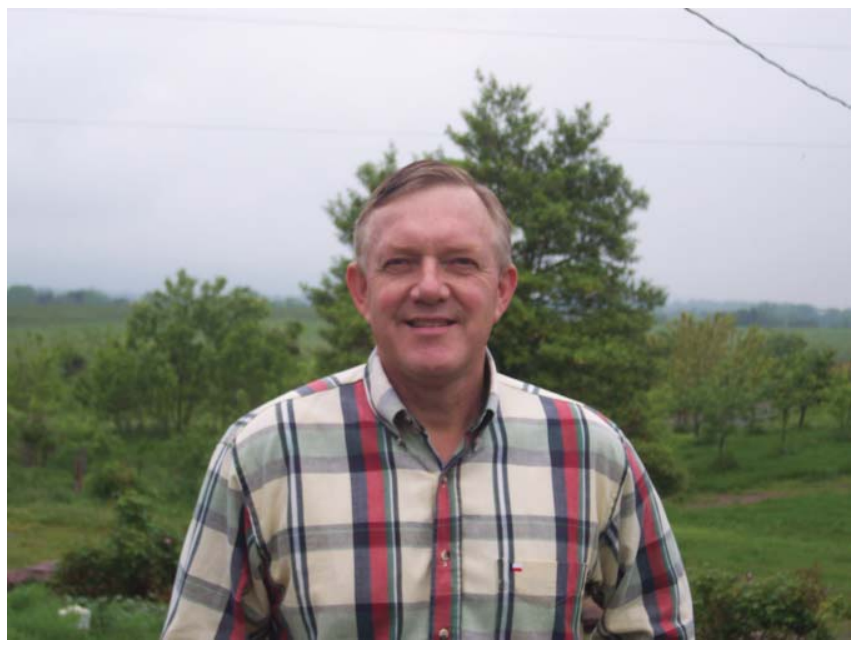

Robert Bolton in the comfortable surroundings of his farm in Maryland.

In the end, this is still a field profession, right?

Absolutely. I work in my current position for the BLM Division Chief and ultimately for the Director. But my job is still to help the people on the ground, and to try and get them the resources they need.

\section{What is the most important thing for you to try to do to help people in the field?}

We need streamlined processes. Right now, field people have to spend huge amounts of time developing volumes of paper work. We need to find ways to streamline this process and get people back on the ground monitoring, applying treatments, and managing these public resources.

\section{Can you accomplish this?}

Yes, there are opportunities. This is really an important issue. Our work force is aging, and the work load is incredible due to the demands created by legislation such as the Freedom of Information Act and the National Environmental Policy Act. Our field people are increasingly frustrated as they spend their time at a desk in front of a computer. We have good people in the field with real field management skills, and we shouldn't be turning them into paralegals.

\section{You see this as a critical issue?}

If the public wants to see our public lands properly managed and improved, then we need to be allowed to let these field people do their jobs. Sometimes I think there are some elements of Society that intentionally exploit federal laws and policies for reasons in which they were not intended, but which serve to keep us from actually doing our jobs. For example, in many areas we are not even able to complete our allotment management plans.

At some point in this interview we probably need to talk about off-road vehicles (ORVs) and water, two of the growing concerns in the west, for various reasons.

Without a doubt, ORVs are a growing impact, and recreation in general has become a major use. We have to work on managing these uses and controlling potential damages. More dialogue among user groups is needed, and education is a key. We are certainly working intensively on this issue through our range management planning efforts.

As for water, I think we have already made huge strides on this issue over several decades. Both the science and technologies for managing riparian areas and watersheds have improved greatly, and our riparian areas and watersheds have benefited. We have really learned how to capture, store, and release water within our watersheds, and this has been a key. In addition, we have certainly learned to start at the upper portions of our watersheds, and have mitigated many of the prior impacts on these landscapes.

Despite some critical issues and concerns, are you quite positive about the directions you are headed?

We have an excellent Director who is grounded in the philosophy of doing the right things on the land. The Department and BLM leadership is supporting us in our Division to develop policies to help resolve some of our issues. We are working to get our people back out on the ground, using their talents, and getting us back to the profession of land management.

Interview was by Susan R. McGuire, a pen name used by the author of this article. Her interviews with members of our profession are a regular contribution to Rangelands. All costs of publishing these interviews are sponsored by a research unit of the Agricultural Research Service, the in-house research agency of the United States Department of Agriculture, whose rangeland scientists are a segment of our Society. 